\title{
Double U-Slot Microstrip Patch Antenna for WLAN and WiMAX Applications
}

\author{
Md. Mahmudur Rahman \\ Assistant Professor \\ Department of Electrical and \\ Electronic Engineering \\ Daffodil International University, \\ Bangladesh
}

\author{
Md. Fokhrul Islam \\ Assistant Professor \\ Department of Electrical and \\ Electronic Engineering \\ Islamic University of Technology, \\ Bangladesh
}

\begin{abstract}
Wireless networks are becoming universal day by day which gives freedom of movement and flexibility in wireless communication. This technology is developing and it has many possibilities in future. Different wireless applications or facilities are available in different frequencies. So, an antenna with multiple frequency bands, which is essential part of this system, has greater acceptance in this regard. In this paper, a dual band rectangular microstrip patch antenna (RMPA) has been proposed for WLAN and WiMAX application. Cutting U-slot inside the patch is used to obtain the dual band characteristics. The dimension of patch of the antenna is $42 \times 26 \times 3.2 \mathrm{~mm}^{3}$ where FR4 material has been used as substrate. The antenna operates in the $2.40 \mathrm{GHz}$ WLAN range and $3.45 \mathrm{GHz}$ WiMAX $(3.2-3.8 \mathrm{GHz})$ range with return loss $-23.3 \mathrm{~dB}$ and $-20.2 \mathrm{~dB}$ respectively. It reaches $5.4 \mathrm{dBi}$ gain and $6.8 \mathrm{dBi}$ directivity at $2.4 \mathrm{GHz}$ and $3.33 \mathrm{dBi}$ gain and 8.1 $\mathrm{dBi}$ directivity at $3.45 \mathrm{GHz}$ resonant frequency. WLAN is widely used for internet connectivity worldwide and the most important application offered by WiMAX Technology is business, consumer connectivity, and backhaul. Hence the proposed antenna is a promising one for practical WLAN and WiMAX devices.
\end{abstract}

\section{Keywords}

Dual-band, WLAN, WiMAX, patch antenna, U-slot

\section{INTRODUCTION}

Antenna, used for transmitting or receiving radio signals, is one of the most important parts of wireless communication system. Several types of antennas are available in practical, but microstrip patch antenna (MPA) is one of the most applicable for wireless communication due to its low profile, light weight, robust nature and low cost of production [1]. A MPA consists of a substrate material which has a metallic patch at one side and a ground plane on the other side of the substrate. The patch is generally made up of copper or gold and the patch can be in any shape such as rectangular, square, circular, elliptical etc. But it has some disadvantages such as low gain, narrow bandwidth and poor efficiency etc. [1].

With the development of wireless communication, applications with wireless communication are growing day by day. WLAN is very important and popular for accessing the internet in many countries. $2.4 \mathrm{GHz}(2.40 \mathrm{GHz}$ to $2.48 \mathrm{GHz})$, $5.2 \mathrm{GHz}(5.15 \mathrm{GHz}$ to $5.35 \mathrm{GHz})$ and $5.8 \mathrm{GHz}(5.72 \mathrm{GHz}$ to $5.82 \mathrm{GHz}$ ) are the bands used for WLAN applications and 2.5 $\mathrm{GHz}(2.5-2.69 \mathrm{GHZ}), 3.5 \mathrm{GHz}(3.4-3.69 \mathrm{GHz})$ and $5.5 \mathrm{GHz}$ $(5.25-5.85 \mathrm{GHz})$ are the three WiMAX licensed spectrum profile [2]. WiMAX is mainly used for residential or home and broadband internet access, medium and small size business, WiFi hotspots, and fixed and portable wireless broadband connectivity which do not need the direct line-ofsight (LOS) along with a base station. So an antenna, operating at more than one frequency, is appropriate as they can incorporate different applications in a single unit.

As the demand for antenna covering more applications in a single unit are increasing day by day, researchers are focusing on patch antenna design resonating at more than one frequency. A dual band $\mathrm{E}$ shape patch antenna working at 2.2 $\mathrm{GHz}$ and $3 \mathrm{GHz}$ is proposed in [3]. A single $\mathrm{U}$ slot patch antenna is proposed in [4] which resonate at $2.31 \mathrm{GHz}$ and $3.78 \mathrm{GHz}$. In [5], a triple band antenna is proposed which resonates at $2 \mathrm{GHz}, 3.5 \mathrm{GHz}$ and $5.6 \mathrm{GHz}$ for UMTS/WiMAX/WLAN applications. A dual-band wearable textile antenna on an EBG substrate is designed in [6] which resonate at $2.45 \mathrm{GHz}$ and $5 \mathrm{GHz}$. There are many ways to incorporate more than one band in a single antenna. But incorporating $U$ slot cutting inside the patch is one of the effective methods to make an antenna dual or multiband [712]. U slot is a combination of two vertical slots and one horizontal slot connected to each other to make the U-slot shape. A MPA basically resonates at a particular frequency with small bandwidth. When a U-slot is inserted inside the patch, a second resonant frequency causes due to the U-slot effect [13].

In this paper, a microstrip patch antenna is designed and analyzed for WLAN and WiMAX application using Zeland IE3D simulation software. The proposed antenna has two resonant frequencies at $2.4 \mathrm{GHz}$ and $3.45 \mathrm{GHz}$ covering WLAN $2.4 \mathrm{GHz}$ and WiMAX $3.45 \mathrm{GHz}$. The gain of the antenna is $5.4 \mathrm{dBi}$ and $3.34 \mathrm{dBi}$ respectively at these two resonant frequencies. And the directivities are $6.8 \mathrm{dBi}$ and 8.1 dBi.

This paper is organized in four sections. A brief introduction of microstrip patch antenna has been given in first section. Design procedure of conventional RMPA and the proposed rectangular MPA has been incorporated in section two. Simulation results are explained in section 3. Section 4 is the concluding part of the paper.

\section{DESIGN METHODOLOGY}

Figure 1 shows a simple RMPA designed for $3.5 \mathrm{GHz}$ resonant frequency. The width $(W)$ and length $(L)$ of the RMPA are calculated following the conventional patch dimension equations [1]. The structure is designed over a FR4 substrate material with thickness $3.2 \mathrm{~mm}$.

The length $(L)$ and the width $(W)$ of the microstrip patch antenna can be approximated by the equations 1 to 5 . For efficient radiation, width $W$ is given by- 


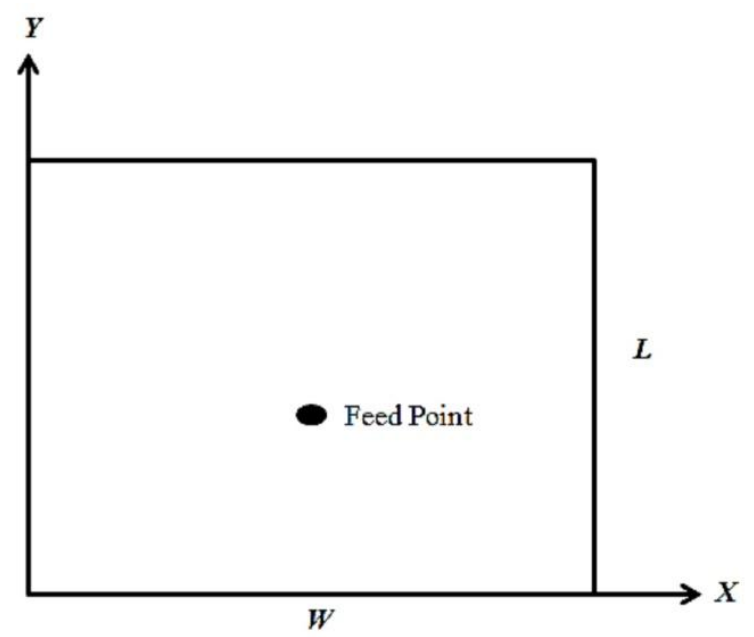

Fig 1: Simple RMPA

$$
W=\frac{c}{2 f_{r} \sqrt{\frac{\varepsilon_{r}+1}{2}}}
$$

Where $c, f_{r}$ and $\varepsilon_{r}$ represents speed of light in free space, resonant frequency and dielectric constant of the substrate respectively. The fields established in the patch are not limited within the patch dimension only, rather it extends outside which is called fringing field $\varepsilon_{e f f}$.

$$
\begin{aligned}
& \varepsilon_{\text {reff }}=\frac{\varepsilon_{r}+1}{2}+\frac{\varepsilon_{r}-1}{2} \times\left[1+12 \frac{h}{W}\right]^{-\frac{1}{2}} \\
& \frac{\Delta L_{\text {eff }}}{h}=0.412 \times \frac{\left(\varepsilon_{\text {reff }}+0.3\right) \times\left(\frac{W}{h}+0.264\right)}{\left(\varepsilon_{\text {reff }}-0.258\right) \times\left(\frac{W}{h}+0.8\right)}
\end{aligned}
$$

The effective length is given by -

$$
L_{e f f}=\left(L+2 \Delta L_{e f f}\right)
$$

The resonant frequency is expressed as -

$$
f_{r}=\frac{c}{2 L_{e f f} \sqrt{\varepsilon_{e f f}}}
$$

Using equations from 1 to 5 dimensions of the patch antenna is calculated. The optimized dimensions of the antenna are given in table 1 .

Table 1: Dimension of the simple RMPA

\begin{tabular}{|c|c|}
\hline Parameters & Optimized Values \\
\hline Length of the main patch, $L$ & $27 \mathrm{~mm}$ \\
\hline Width of the main patch, $W$ & $42 \mathrm{~mm}$ \\
\hline $\begin{array}{c}\text { Height of the dielectric substrate, } h \\
\text { Dielectric constant of the dielectric } \\
\text { substrate, } \varepsilon_{r}\end{array}$ & $3.2 \mathrm{~mm}$ \\
\hline
\end{tabular}

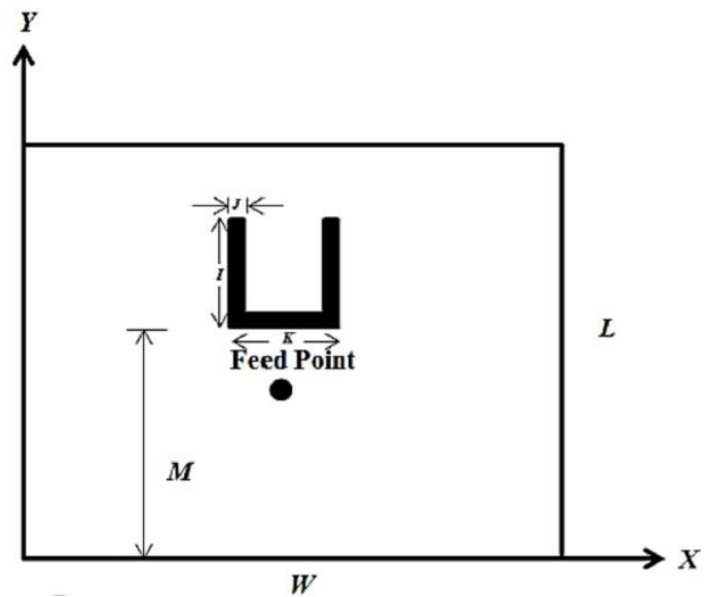

Fig 2: RMPA with single U-slot

To introduce a resonance frequency at the same resonant frequency $3.43 \mathrm{GHz}$ a U-slot is introduced inside the patch. As the patch and the $U$ slot resonate almost at same frequency, this will decrease the value of return loss at that resonant frequency. The patch antenna with U-slot is shown in figure 2 .

The optimized values of the dimensions of the first U-slot are provided in table 2 . Length, width, substrate material and height of the substrate remains same mentioned in table 1 for simple RMPA.

Table 2: Dimension of the first U slot

\begin{tabular}{|c|c|}
\hline Parameters & Optimized values \\
\hline Thickness of the U slot, $J$ & $1 \mathrm{~mm}$ \\
\hline Width of the slot, $K$ & $5 \mathrm{~mm}$ \\
\hline Height of the slot, $I$ & $4.5 \mathrm{~mm}$ \\
\hline Height of slot from base of patch, $M$ & $17.2 \mathrm{~mm}$ \\
\hline
\end{tabular}

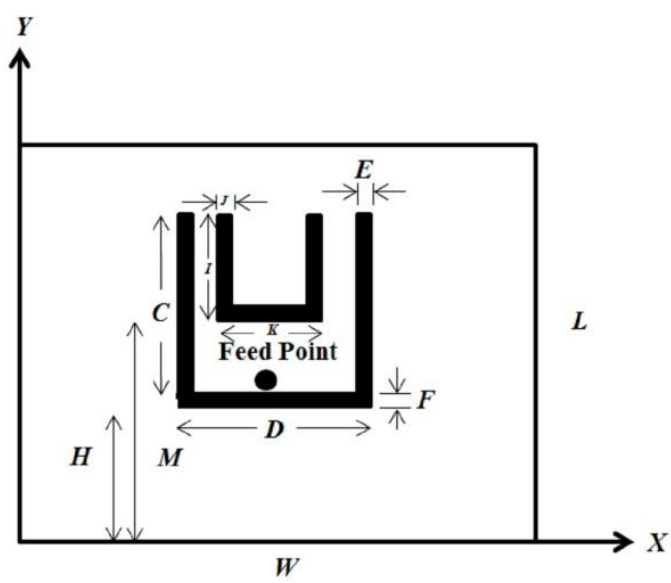

Fig 3: RMPA with two U-slots

The antenna gives the first resonant frequency due to patch itself and small U slot. And it resonates at another frequency for the insertion of second $U$ slot inside the patch.

To create another resonant frequency at $2.4 \mathrm{GHz}$ for WLAN applications second $U$ slot is inserted inside the patch which in bigger in size than that of previous one. Figure 3 shows the modified antenna with two U-slots inside the patch. 
The optimized values of various dimensions of the second $U$ slot are provided in table 3 .

Table 3: Dimension of the second U slot

\begin{tabular}{|c|c|}
\hline Parameters & Optimized values \\
\hline Thickness of U slot, $E=F$ & $1 \mathrm{~mm}$ \\
\hline Width of the slot, $D$ & $9 \mathrm{~mm}$ \\
\hline Height of the slot, $C$ & $7 \mathrm{~mm}$ \\
\hline Height of slot from base of patch, $H$ & $13.8 \mathrm{~mm}$ \\
\hline
\end{tabular}

\section{RESULT AND SIMULATION}

The performance of the antenna structures is analyzed by Zeland IE3D simulation software. The simple RMPA resonates at $3.43 \mathrm{GHz}$ with bandwidth and return loss of 90 $\mathrm{MHz}(3.39-3.48 \mathrm{GHz})$ and $-14.9 \mathrm{~dB}$ respectively. The maximum gain and the directivity of the simple RMPA at $3.43 \mathrm{GHz}$ are $3.38 \mathrm{dBi}$ and $8.35 \mathrm{dBi}$. This frequency is in the region of WiMAX frequency range. Figure 04 depicts the return loss of the simple patch antenna.

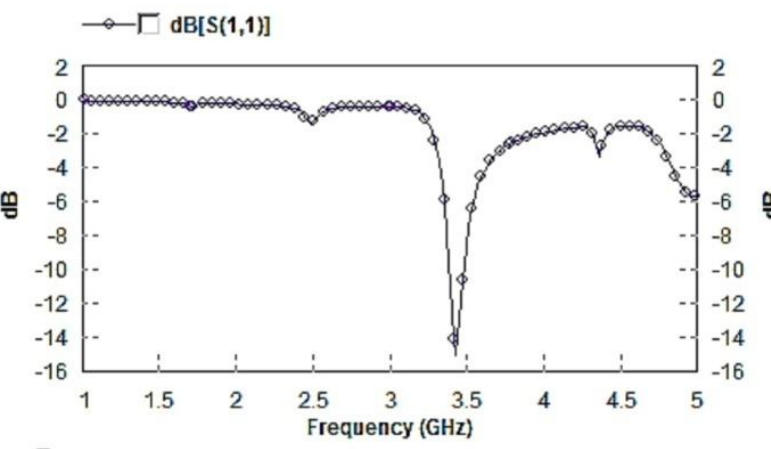

Fig 4: Reflection coefficient (S11) of simple RMPA

After the insertion of the first U-slot, the patch antenna resonates at $3.4 \mathrm{GHz}$. With the addition of this U-slot return loss at $3.4 \mathrm{GHz}$ decreases to $-21.4 \mathrm{~dB}$ where the return loss at $3.43 \mathrm{GHz}$ was $-14.9 \mathrm{~dB}$ for simple patch without U-slot.

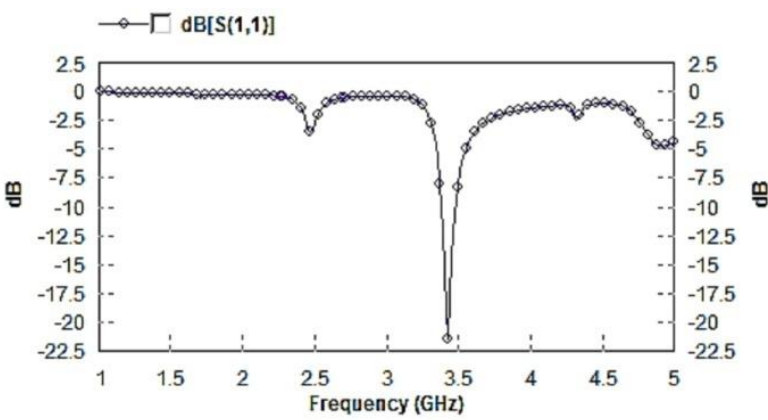

Fig 5: Reflection coefficient (S11) of RMPA with single Uslot

Bandwidth, gain and directivity at this resonant frequency is $100 \mathrm{MHz}(3.38-3.48 \mathrm{GHz}), 3.45 \mathrm{dBi}$ and $8.4 \mathrm{dBi}$ respectively. Figure 05 depicts the return loss of the simple patch antenna with single U slot.

After the addition of second U-slot inside the patch, a second resonant frequency is introduced inside the patch at $2.4 \mathrm{GHz}$. The bandwidth and return loss at $2.4 \mathrm{GHz}$ frequency is 70 $\mathrm{MHz}$ and $-23.2 \mathrm{~dB}$. And the maximum gain and directivity of the antenna is $5.4 \mathrm{dBi}$ and $6.8 \mathrm{dBi}$ respectively. Then the antenna acts as a dual band antenna resonating at $2.4 \mathrm{GHz}$ at WLAN range and $3.45 \mathrm{GHz}$ at WiMAX range. Bandwidths of the proposed antenna at the two resonant frequencies are 70 $\mathrm{MHz} \quad(2.38-2.45 \mathrm{GHz})$ and $80 \mathrm{MHz}(3.42-3.5 \mathrm{GHz})$ respectively and the return loss are $-23.2 \mathrm{~dB}$ and $-20.3 \mathrm{~dB}$ respectively at $2.4 \mathrm{GHz}$ and $3.45 \mathrm{GHz}$. The Gains of the proposed antenna at these two resonant frequencies are 5.4 $\mathrm{dBi}$ and $3.34 \mathrm{dBi}$ respectively and the directivities are $6.8 \mathrm{dBi}$ and $8.1 \mathrm{dBi}$ respectively. Figure 6 depicts the return loss of the proposed antenna.

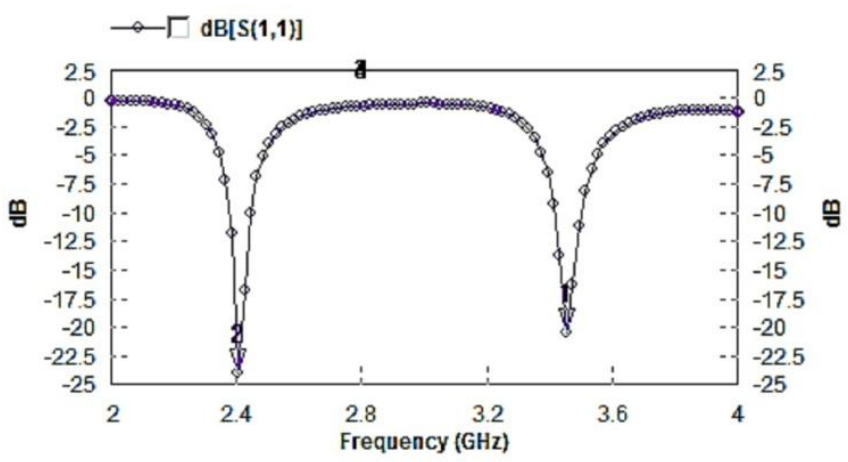

Fig 6: Reflection coefficient (S11) of RMPA with double U-slot

Table 4 shows a comparison between various parameters of the mentioned three structures.

Table 4: Parameter comparison of antennas

\begin{tabular}{|c|c|c|c|c|}
\hline $\begin{array}{c}\text { Antenna } \\
\text { parameters }\end{array}$ & RMPA & $\begin{array}{c}\text { Single } \\
\text { U slot }\end{array}$ & \multicolumn{2}{|c|}{ Double U slot } \\
\hline $\begin{array}{c}\text { Resonant } \\
\text { frequency }(\mathrm{GHz})\end{array}$ & 3.43 & 3.4 & 2.4 & 3.45 \\
\hline Return loss (dB) & -14.9 & -21.4 & -23.2 & -20.3 \\
\hline Bandwidth (MHz) & 90 & 100 & 70 & 80 \\
\hline Gain (dBi) & 3.38 & 3.45 & 5.4 & 3.34 \\
\hline Directivity (dBi) & 8.35 & 8.4 & 6.8 & 8.1 \\
\hline
\end{tabular}

Figure 7 and 8 depicts average and vector current distribution of proposed antenna which confirms that it shows linear polarization. Figure 9 to 12 shows the radiation pattern of the proposed antenna where figure 9 and 10 is for gain and figure 11 and 12 shows the directivity gain.

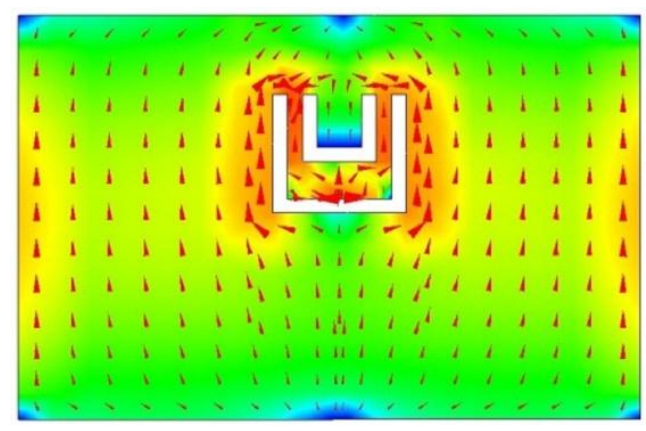

Fig 7: Average and vector current distribution at $2.4 \mathrm{GHz}$ 


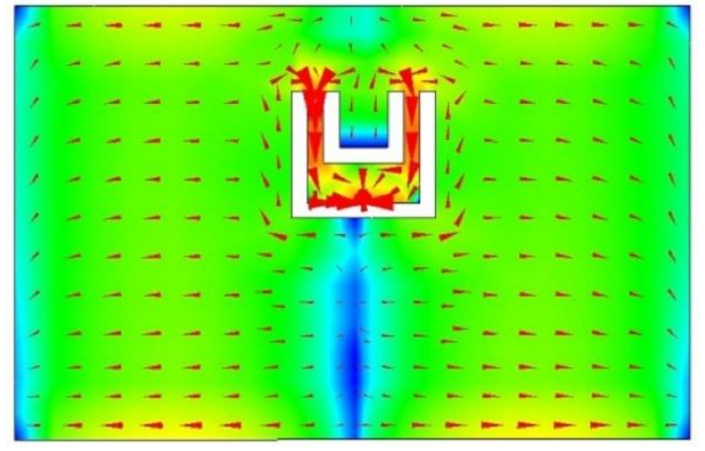

Fig 8: Average and vector current distribution at $3.45 \mathrm{GHz}$

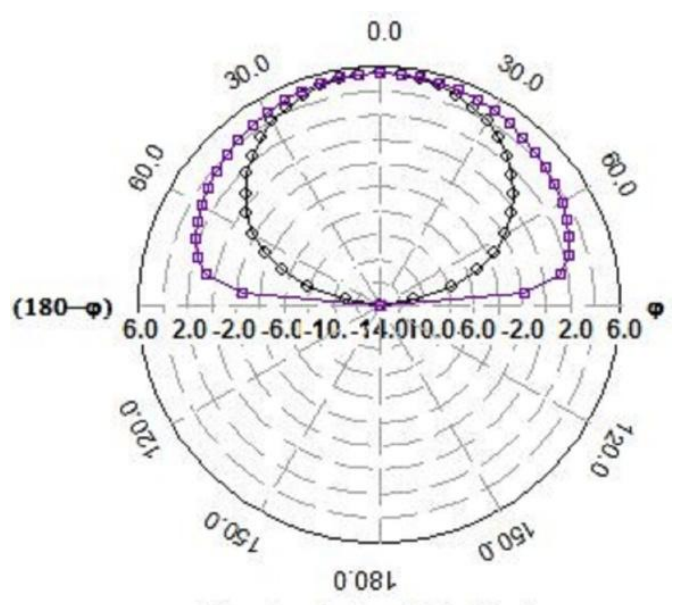

Elevation Pattern Gain Display (dBi)

Fig 9: Antenna Gain at $2.4 \mathrm{GHz}$

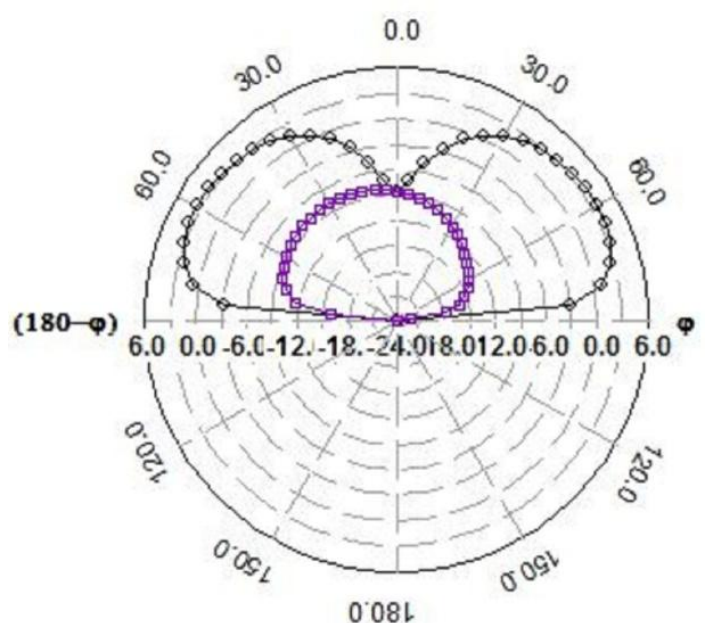

Elevation Pattern Gain Display (dBi)

Fig 10: Antenna Gain at $3.45 \mathrm{GHz}$

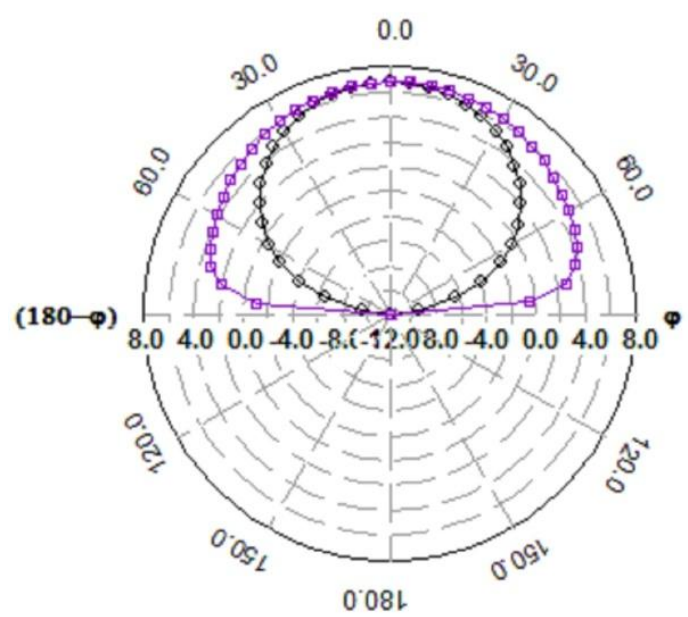

Elevation Pattern Directivity Display (dBi)

Fig 11: Antenna directivity at $2.4 \mathrm{GHz}$

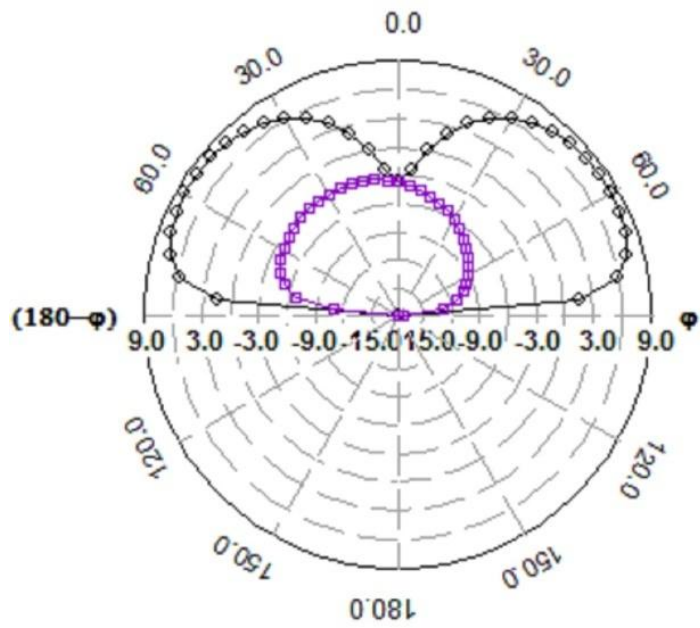

Elevation Pattern Directivity Display (dBi)

Fig 12: Antenna directivity at $3.45 \mathrm{GHz}$

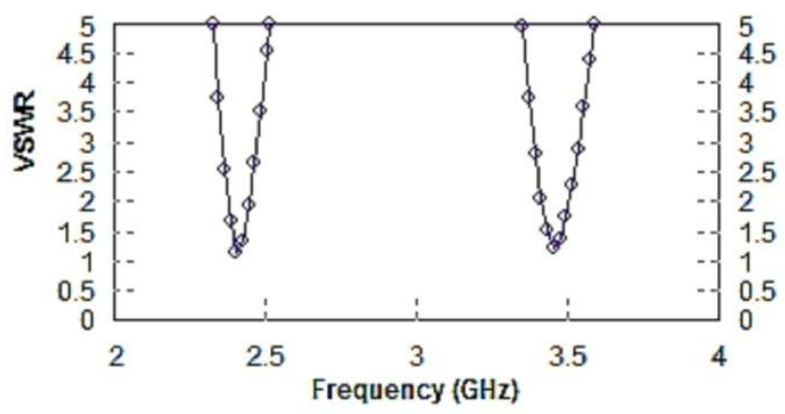

Fig 13: VSWR graph of the proposed antenna

The VSWR of the proposed antenna at $2.4 \mathrm{GHz}$ and $3.45 \mathrm{GHz}$ is 1.14 and 1.21 respectively. Figure 13 shows the VSWR of the proposed antenna. 


\section{CONCLUSION}

A simple double U-slot microstrip patch antenna is proposed in this paper for WLAN and WiMAX applications. Double Uslots are used inside the patch to achieve dual band operation and improved characteristics with respect to simple RMPA. The proposed antenna resonates at $2.4 \mathrm{GHz}$ and $3.45 \mathrm{GHz}$ due to the insertion of large and small U-slot respectively inside the patch and shows linear polarization. The maximum gain of the proposed antenna is $5.4 \mathrm{dBi}$ and $3.34 \mathrm{dBi}$ respectively and the directivity is $6.8 \mathrm{dBi}$ and $8.1 \mathrm{dBi}$ respectively at these two resonant frequencies. The proposed antenna is suitable for all applications under WLAN and WiMAX frequency band. Further modification can be done to get wideband characteristics or to further enhance the gain and directivity of the proposed antenna. Also, a single or multiband antenna at any desired frequency can be designed with proper designing and modification of the proposed antenna.

\section{REFERENCES}

[1] Waheed Mohmmed Khan, Sanjay M. Gulhane, "Related review on microstrip patch antennas", International Journal of Industrial Electronics and Electrical Engineering, ISSN: 2347- 6982 Volume-3, Issue-1, Jan.2015.

[2] M. Samsuzzaman, T. Islam, N. Abd Rahman, M. R. I. Faruque, and J. Mandeep, "Compact modified swastika shape patch antenna for WLAN/WiMAX applications," International Journal of Antennas and Propagation, vol. 2014, 2014

[3] P. Salonen, J. Kim, and Y. Rahmat-Samii, "Dual-band Eshaped patch wearable textile antenna," in 2005 IEEE Antennas and Propagation Society International Symposium, 2005, pp. 466-469.

[4] J. Ghalibafan, A. R. Attari, and F. Hojjat-Kashani, "A new dual-band microstrip antenna with U-shaped slot," Progress In Electromagnetics Research C, vol. 12, pp. 215-223, 2010.
[5] S. Mathew, M. Ameen, M. Jayakrishnan, P. Mohanan, and K. Vasudevan, "Compact dual polarised V slit, stub and slot embedded circular patch antenna for UMTS/WiMAX/WLAN applications," Electronics Letters, vol. 52, pp. 1425-1426, 2016.

[6] S. Zhu and R. Langley, "Dual-band wearable textile antenna on an EBG substrate," IEEE Transactions on Antennas and Propagation, vol. 57, pp. 926-935, 2009.

[7] S. Liu, S. S. Qi, W. Wu, and D. G. Fang, "Single-Layer Single-Patch Four-Band Asymmetrical U-Slot Patch Antenna," IEEE Transactions on Antennas and Propagation, vol. 62, pp. 4895-4899, 2014.

[8] K. F. Lee, S. L. S. Yang, and A. A. Kishk, "U-slot patch antennas for dual-band or multi-band applications," in Antenna Technology, 2009. iWAT 2009. IEEE International Workshop on, 2009, pp. 1-4.

[9] K. F. Lee, S. L. S. Yang, A. A. Kishk, and K. M. Luk, "The versatile U-slot patch antenna," IEEE Antennas and Propagation Magazine, vol. 52, pp. 71-88, 2010.

[10] K. F. Lee, K. Luk, K. Mak, and S. Yang, "On the use of U-slots in the design of dual-and triple-band patch antennas," IEEE Antennas and Propagation Magazine, vol. 53, pp. 60-74, 2011

[11] W. C. Mok, S. H. Wong, K. M. Luk, and K. F. Lee, "Single-layer single-patch dual-band and triple-band patch antennas," IEEE transactions on antennas and propagation, vol. 61, pp. 4341-4344, 2013.

[12] M. S. Habib, I. M. Rafiqul, K. Abdullah, and M. J. Jakpar, "U-slot rectangular patch antenna for dual band application," in Advanced Computer and Communication Engineering Technology, ed: Springer, 2015, pp. 111120.

[13] R. Bhalla and L. Shafai, "Resonance behavior of single U-slot microstrip patch antenna," Microwave and Optical Technology Letters, vol. 32, pp. 333-335, 2002. 